\title{
Acetaminophen attenuates lipopolysaccharide-induced cognitive impairment through antioxidant activity
}

Wei-Xing Zhao ${ }^{1 \dagger}$, Jun-Han Zhang ${ }^{2 \dagger}$, Jiang-Bei Cao ${ }^{1}$, Wei Wang ${ }^{1,3}$, Dong-Xin Wang ${ }^{4}$, Xiao-Ying Zhang ${ }^{1}$, Jun Yu', Yong-Yi Zhang ${ }^{1}$, You-Zhi Zhang ${ }^{5 \dagger}$ and Wei-Dong $\mathrm{Mi}^{1^{*+}}$

\begin{abstract}
Background: Considerable evidence has shown that neuroinflammation and oxidative stress play an important role in the pathophysiology of postoperative cognitive dysfunction (POCD) and other progressive neurodegenerative disorders. Increasing evidence suggests that acetaminophen (APAP) has unappreciated antioxidant and anti-inflammatory properties. However, the impact of APAP on the cognitive sequelae of inflammatory and oxidative stress is unknown. The objective of this study is to explore whether APAP could have neuroprotective effects on lipopolysaccharide (LPS)induced cognitive impairment in mice.
\end{abstract}

Methods: A mouse model of LPS-induced cognitive impairment was established to evaluate the neuroprotective effects of APAP against LPS-induced cognitive impairment. Adult C57BL/6 mice were treated with APAP half an hour prior to intracerebroventricular microinjection of LPS and every day thereafter, until the end of the study period. The Morris water maze was used to assess cognitive function from postinjection days 1 to 3. Animal behavioural tests as well as pathological and biochemical assays were performed to evaluate LPS-induced hippocampal damage and the neuroprotective effect of APAP.

Results: Mice treated with LPS exhibited impaired performance in the Morris water maze without changing spontaneous locomotor activity, which was ameliorated by treatment with APAP. APAP suppressed the accumulation of pro-inflammatory cytokines and microglial activation induced by LPS in the hippocampus. In addition, APAP increased SOD activity, reduced MDA levels, modulated glycogen synthase kinase $3 \beta$ (GSK3 3 ) activity and elevated brain-derived neurotrophic factor (BDNF) expression in the hippocampus. Moreover, APAP significantly decreased the Bax/BCl-2 ratio and neuron apoptosis in the hippocampus of LPS-treated mice.

Conclusions: Our results suggest that APAP may possess a neuroprotective effect against LPS-induced cognitive impairment and inflammatory and oxidative stress via mechanisms involving its antioxidant and anti-inflammatory properties, as well as its ability to inhibit the mitochondrial permeability transition (MPT) pore and the subsequent apoptotic pathway.

Keywords: Acetaminophen, Neuroprotective therapy, Antioxidant activity, Oxidative stress, Neuroinflammation, Memory impairment, Apoptosis

\footnotetext{
*Correspondence: wwdd1962@aliyun.com

Wei-Xing Zhao and Jun-Han Zhang are co-first authors

${ }^{\dagger}$ Equal contributors

${ }^{1}$ Anesthesia and Operation Center, Chinese PLA General Hospital, 28th

Fuxing Road, Haidian District, Beijing 100853, China

Full list of author information is available at the end of the article
} 


\section{Background}

Postoperative cognitive dysfunction (POCD) is characterized by a decline in cognitive function that occurs in patients after anaesthesia and surgery when compared to their preoperative cognitive status [1]. The decreased cognitive functions include impairments in working memory, long-term memory, information processing, attention and cognitive flexibility [2, 3]. The incidence of POCD indicates increased risk of mortality, decreased quality of life, risk of early withdrawal from the workforce and increased dependency [4]. There is emerging evidence that neuroinflammation is implicated in the pathophysiology of POCD and other progressive neurodegenerative disorders such as Alzheimer's disease (AD), Parkinson's disease, amyotrophic lateral sclerosis (ALS) and multiple sclerosis (MS) [5-7]. Evidence has also shown that oxidative stress is harmful to cognitive function and is thought to contribute to the pathogenesis of the above neurodegenerative diseases [8-10]. In fact, neuroinflammation and oxidative stress exist simultaneously, and the interaction between oxygen free radicals and inflammatory factors aggravates cognitive deficiency $[11,12]$. However, the exact pathogenesis underlying the effect of neuroinflammation and oxidative stress on cognitive function is still unclear.

Lipopolysaccharide (LPS) is a major bacterial TLR4 ligand that activates the innate immune response to infections [13]. Intracerebroventricular administration of LPS in mice produces cognitive impairment by expression of pro-inflammatory cytokines and neuronal death via apoptosis [14-19], and oxidative stress induced by LPS has been implicated in memory impairment [20]. This method can be effectively used as an animal model for POCD $[15,19]$.

Acetaminophen ( $N$-acetyl-4-aminophenol), also known as APAP or paracetamol, is one of the most widely used medications all over the world. APAP exhibits both analgesic and antipyretic properties and has been widely used as an active ingredient in many approved drugs. Additionally, since the 1980s, APAP has become the first drug of choice for the treatment of pain and fever in children due to the high incidence of Reye's syndrome associated with aspirin [21]. According to the US Food and Drug Administration (FDA), 479 drugs contain APAP. As of August 2011, 235 out of the 479 APAPcontaining drugs have an active approval status, including 214 prescription drug products owned by 31 companies and 21 over-the-counter (OTC) drug products produced by nine companies [22]. Given its wide use and easy availability, scientists have recently begun to examine APAP for off-label applications [22].

It has also been reported that APAP has neuroprotective effects. Maharaj et al. [23] reported that APAP (0.25-1 $\mathrm{mM})$ treatment ex vivo can inhibit cyanide- induced superoxide anion generation and lipid peroxidation in rat brain homogenates. Further animal study has suggested that APAP (100 mg/kg/day, i.p.) can inhibit quinolinic acid (QA)-induced lipid peroxidation, superoxide anion generation, and cell damage in the rat hippocampus [24]. Tripathy et al. [25, 26] showed that low-dose APAP reduces inflammatory protein release from cultured brain neuronal and endothelial cells exposed to oxidant stress and increases expression of the anti-apoptotic protein Bcl2 in brain neurons. Naziroglu et al. [27] also reported that APAP $(5-100 \mathrm{mg} / \mathrm{kg}$ ) can reduce brain and microsomal lipid peroxidation, while it also increases brain vitamin $\mathrm{E}$ levels and microsomal glutathione peroxidase (GSH-Px) activity. In addition, APAP has been shown to protect dopaminergic neurons from oxidative damage evoked by acute exposure to 6-hydroxydopamine or excessive levels of dopamine in vitro [28], suggesting a potential benefit for PD. Finally, recent studies have shown that APAP shows nootropic activity through increasing the escape latency in the step through passive avoidance paradigm task and decreasing acetyl cholinesterase activity in colchicineinduced cognitive impairment (an animal model for AD) in rats [29], suggesting a possible therapeutic effect of APAP in AD.

Based on the above findings, we hypothesized that during neuroinflammation, APAP might attenuate oxidative stress and inflammatory cytokines in the hippocampus and thus improve cognitive impairment. To test this hypothesis, we assessed the neuroprotective effects of APAP against LPS-induced neuroinflammation and oxidative damage in the present study. The results obtained in this study may provide new insight into the mechanism of APAP for the treatment of cognitive impairment.

\section{Methods \\ Animals}

Adult male C57BL/6 $(n=80)$ mice aged $10-11$ weeks and weighing 21-23 g were purchased from Vital River Laboratories Animal Technology Co. Ltd. (Beijing, China. Permit Number: SCXK(JING) 2012-0001). All mice were housed in groups of 3 to 5 per plastic cage $(24 \times 36 \times 24 \mathrm{~cm})$ and given free access to standard food and water in an air-conditioned room set at $24 \pm 1{ }^{\circ} \mathrm{C}$ with $50 \pm 10 \%$ humidity, under a standard 12-12 lightdark cycle (lights on 7 AM to 7 PM). The animals were acclimatized for 7 days before the experiment and were group-housed with the same cage mates throughout the acclimation and testing periods. The procedures on animal experimentation were approved by the Animal Care Committee of the Chinese People's Liberation Army General Hospital (Beijing, China). The maintenance and handling of the mice were consistent with the guidelines 
of the National Institutes of Health, and adequate measures were taken to minimize animal discomfort.

\section{Drug treatment}

The mice were divided into four groups randomly (20 mice per group): the control plus placebo group (CON group), control plus APAP group (APAP group), LPS plus placebo group (LPS group) and the LPS plus APAP group (A $+\mathrm{L}$ group). The LPS-induced cognitive impairment mouse model was performed according to a protocol previously described by our laboratory [19]. LPS was administered via the intracerebroventricular (i.c.v.) route. Each mouse was anaesthetized with chloral hydrate $(400 \mathrm{mg} / \mathrm{kg}$, i.p.). LPS (Sigma, St. Louis, MO, USA), dissolved in artificial cerebrospinal fluid (aCSF: $140 \mathrm{mM}$ $\mathrm{NaCl}, 3.0 \mathrm{mM} \mathrm{KCl}, 2.5 \mathrm{mM} \mathrm{CaCl}, 1.0 \mathrm{mM} \mathrm{MgCl} 2$ and $\left.1.2 \mathrm{mM} \mathrm{Na}_{2} \mathrm{HPO}_{4}\right)$ with $\mathrm{pH}=7.4(2 \mu \mathrm{g}$ in $2 \mu \mathrm{L})$, was infused into the lateral ventricle using a mouse brain stereotactic apparatus (Kopf Instruments, Tujunga, CA, USA). The stereotactic coordinates from bregma were derived according to Zhang [19]. The coordinates were $0.5 \mathrm{~mm}$ caudal to bregma, $1.0 \mathrm{~mm}$ right lateral to the sagittal suture and $2.0 \mathrm{~mm}$ ventral of the dura. Using a $10-\mu \mathrm{L}$ microsyringe, the injection speed was set at $0.667 \mu \mathrm{L} / \mathrm{min}$ and the needle was held in place for 2 min for proper dispersal of the drug from the tip following injection.

In mice in the CON group and APAP group, $2 \mu \mathrm{L}$ of aCSF was infused into the lateral ventricle. Mice in the LPS group and A $+\mathrm{L}$ group were infused with LPS. Animals in the APAP group and $\mathrm{A}+\mathrm{L}$ group received intraperitoneal injections of APAP $(100 \mathrm{mg} / \mathrm{kg} /$ day $)$ from day 0 starting $30 \mathrm{~min}$ prior to receiving the LPS injection, until the end of the study period. Meanwhile, an equivalent volume of vehicle (saline solution) for APAP was given to the CON and LPS groups. The dosage of the drug was chosen according to the results of our preliminary study and is consistent with previous literature sources where the agent was shown to have neuroprotective effects [23, 24].

\section{Behavioural tests}

\section{Open field test (OFT)}

To evaluate whether the lesioned performance by LPS were attributable to changes in spontaneous locomotor activity, anxiety and adaptivity to the Morris water maze test, open field tests were performed $2 \mathrm{~h}$ before the probe test for reference memory. A number of 10 mice in each group (40 mice in total) were randomly selected and subjected to behavioural test in this study. The open field test was performed according to the previous study [30]. The open field apparatus is a black woody box $(50 \times 50 \times 30 \mathrm{~cm})$; the floor was divided into two concentric square shape zones representing the close and far distance to the central of the field. The test was performed under a dark light of $50 \mathrm{~lx}$. Mice were placed in the centre of the open field and allowed a 5-min acclimation period. Their activities were recorded by an overhead video camera. The total moving distance as well as the moving duration in the open field was analysed using animal behavioural tracking system (Smart, San Diego Instruments, San Diego, CA, USA). The open field apparatus was thoroughly cleaned with $5 \%$ ethyl alcohol after the test of each mouse and allowed to dry between tests.

\section{Morris water maze (MWM)}

The MWM test, which is a hippocampal-dependent test of spatial learning, spatial memory and cognitive flexibility for rodents, was performed as described previously with minor modifications [31]. The water maze was a white circular tank made of polyvinyl chloride $(118 \mathrm{~cm}$ in diameter and $42 \mathrm{~cm}$ in height) and filled with white non-toxic paint and water $\left(23 \pm 1{ }^{\circ} \mathrm{C}\right)$ to a depth of $28 \mathrm{~cm}$. The maze was placed in a room with several visual cues for orientation in the maze. The maze was divided into four quadrants: the first, second, third and fourth quadrants. An invisible platform (11 $\mathrm{cm}$ in diameter) was placed $1 \mathrm{~cm}$ below the water surface in the first quadrant (target quadrant). Spatial learning is assessed across repeated trials for 3 days (day -3 to day -1 ). Mice received one training session consisting of eight trials per day for continuous 3 days (day -3 (training session 1); day -2 (training session 2); day -1 (training session 3)). Mice were released into the water facing the wall of the tank from one of four separate quadrants and were allowed to escape onto the hidden platform. The submerged platform was always located in the first quadrant. A different starting point was used on the eight trials. The mice were trained to find the hidden platform and climb onto it within $60 \mathrm{~s}$. The animals were allowed to stay on the platform for at least $10 \mathrm{~s}$ after each trial. When the mice failed to reach the escape platform within $60 \mathrm{~s}$, they were manually guided to the platform for $10 \mathrm{~s}$ by the experimenter. After that, the mouse was removed to its cage and the second animal was tested on trial 1 . This rotation was repeated until all animals completed trial 1. Subsequently, the process was repeated for subsequent trials until eight trials completed per day for three consecutive days. After each trial, animals were towel dried and returned to their home cage under a heater for $10 \mathrm{~min}$. The animals' movements were recorded with a video camera attached to the ceiling.

On day 0 , animals underwent LPS microinjection. On postoperative day 1 , probe tests for reference memory were conducted on all the treated groups by removing the hidden platform and releasing the mice in the third quadrant (opposite to the first quadrant). Swimming 
speed, platform-site crossings, time travelled in the target quadrant, the percentage of distance travelled in the target quadrant and distance around the platform were recorded in a single 60-s trial. Reference memory was determined by preference for the platform area.

On days 1, 2 and 3, working memory was tested, during which both the platform and mice were randomly placed in a novel position to assess working- or trialdependent learning and memory [31]. In this procedure, the animal is given two trials per day. On each day, animals underwent the first training trial to ensure that all mice learned the new platform location. After $15 \mathrm{~s}$, the second trial is the test trial or matching trial in which each mouse was released from the same location as in the first trial; if it recalled the first trial, the mice would swim a shorter path to the platform in the second trial. As the platform is moved daily, learning of platform position from the previous day cannot be transferred to the next day; hence, recall on each day during the second trial is dependent on that day's training trial and measures only temporary or working memory. Measurement of data on the second trial was conducted up to $60 \mathrm{~s}$ and the latency for mice that could not reach the platform in the allotted time was regarded as $60 \mathrm{~s}$. Eventually, the escape latency to the platform in the second trial was recorded as measure of temporary or working memory.

\section{Tissue sampling}

At 6, 24, 48 and $72 \mathrm{~h}$ after administration of LPS, the mice were sacrificed by cervical decapitation under deep pentobarbital sodium anesthesia. Transcardial perfusion was performed with ice-cold standard phosphatebuffered saline (PBS). The brains of six mice sacrificed at $24 \mathrm{~h}$ in each group were quickly removed and fixed in $4 \%$ paraformaldehyde for $48 \mathrm{~h}$ for histological analysis. Then, the other brains were immediately removed and washed in ice-cold saline. The hippocampus was dissected and collected carefully in a sterile tube prior to being snap-frozen in liquid nitrogen. The hippocampi were stored at $-80{ }^{\circ} \mathrm{C}$ until analysis. Hippocampi of mice killed at $6 \mathrm{~h}$ were used for an enzyme-linked immunosorbent assay (ELISA) for measuring inflammatory cytokines. As previously recorded [32-35], LPS activates microglia and induces pro-inflammatory protein secretion within $6 \mathrm{~h}$ in the mouse hippocampus via the NF- $\mathrm{kB}$ pathway. All other tests were carried out on post-administration day 1 , which corresponded to the time point of the peak behavioural deficits.

\section{ELISA}

Concentrations of interleukin-1 $\beta$ (IL-1 $\beta$ ), interleukin-6 (IL-6), and tumour necrosis factor $\alpha$ (TNF- $\alpha$ ) were examined using an ELISA kit following the manufacturer's instructions (Biosource, Invitrogen, USA). Hippocampal tissue was homogenized in RIPA lysis buffer $(50 \mathrm{mmol} / \mathrm{L}$ Tris- $\mathrm{HCl}, \mathrm{pH}$ 6.8, $150 \mathrm{mmol} / \mathrm{L} \mathrm{NaCl}, 5 \mathrm{mmol} / \mathrm{L}$ EDTA, $0.5 \%$ sodium deoxycholate, $0.5 \% \mathrm{NP}-40$ ) and supplemented with a cocktail containing protease and phosphatase inhibitors (Applygen, Beijing, China) on ice. Supernatant protein concentrations were determined after centrifugation at $12,000 \mathrm{rpm}$ for $30 \mathrm{~min}$ with a BCA Protein Assay reagent kit (Thermo Pierce, Rockford, IL, USA). For each sample, $5 \mu \mathrm{L}$ of extracted protein was used for detection. The procedure followed the manufacturer's instructions. The absorbance was read on a spectrophotometer at a wavelength of $450 \mathrm{~nm}$ and a reference wavelength of $650 \mathrm{~nm}$. The concentrations of IL- $1 \beta$, IL- 6 and TNF- $\alpha$ were calculated according to the standard curve and presented as $\mathrm{pg} / \mathrm{mg}$ protein.

\section{Immunohistochemistry staining}

A cerebral block containing the hippocampus and prefrontal cortex was fixed in $10 \%$ neutral-buffered formalin overnight and then embedded in paraffin. Coronal 10$\mu \mathrm{m}$ sections were prepared and subjected to immunohistochemistry staining. First, paraffin sections were dewaxed and placed in EDTA buffer ( $\mathrm{pH} \mathrm{8.0)}$ to repair antigens. Second, sections were washed in $0.01 \%$ Triton $\mathrm{X}-100$ in phosphate-buffered saline (PBS-T) and blocked with $3 \%$ bovine serum albumin (BSA) for $30 \mathrm{~min}$ at room temperature. Then, they were incubated overnight at $4{ }^{\circ} \mathrm{C}$ in the appropriate primary antibody, anti-Iba1 (1:100; WAKO). Next, the sections were incubated with the appropriate secondary antibody, anti-rabbit IgG (1:400; Jackson) for $2 \mathrm{~h}$ at room temperature. Glial reactivity is characterized by an increase in the number of cells and an alteration in cell morphology (rounding of the cell bodies and thickening of processes), which leads to an increase in Iba1 (ionized calcium-binding adaptor molecule 1) labelling with increasing glial reactivity. An increase in the integrated intensity/pixel area for Iba1 staining was interpreted to signify microglial reactivity. The number of positively stained microglial cells per view was counted using microscopy at $\times 200$ magnification. Images were captured using the Olympus BX5 imaging system and quantified using Image-Pro Plus 6.0 software.

\section{Biochemical analysis Malondialdehyde (MDA)}

MDA is a degraded oxidative lipid product from cell membranes and is used as a reliable indicator of oxidative stress [36]. The amount of MDA was measured by the reaction of one molecule of MDA with two molecules of TBA to yield a pink coloured chromogen. The colour reaction was measured at $532 \mathrm{~nm}$ with a reference wavelength at $450 \mathrm{~nm}$. The levels of MDA in the hippocampi of mice were measured using commercial 
assay kits (Beyotime Biotechnology Institute, Nantong, China) according to the manufacturer's instructions.

\section{Superoxide dismutase (SOD) activity}

SOD is an endogenous scavenger of reactive oxygen species (ROS) and is one of the major antioxidant enzyme involved in protecting the nerve tissue from oxidative stress. The activity of SOD was measured by the reaction of NBT (nitro blue tetrazolium) with two molecules of superoxide anion to yield a blue coloured chromogen, and SOD has the ability to inhibit the superoxide anion free radical $\mathrm{O}_{2}^{-}$. The colour reaction was measured at $560 \mathrm{~nm}$ with a reference wavelength at $650 \mathrm{~nm}$. The SOD activity of tissue was also measured using commercial assay kits (Beyotime Biotechnology Institute, Nantong, China) according to the manufacturer's instructions.

\section{Western blot analysis}

Hippocampal tissue was homogenized in RIPA lysis buffer $(50 \mathrm{mmol} / \mathrm{L}$ Tris- $\mathrm{HCl}, \mathrm{pH} 6.8,150 \mathrm{mmol} / \mathrm{L} \mathrm{NaCl}$, $5 \mathrm{mmol} / \mathrm{L}$ EDTA, $0.5 \%$ sodium deoxycholate, $0.5 \% \mathrm{NP}-$ 40) plus protease inhibitor and phosphatase inhibitor cocktail (Applygen, Beijing, China) on ice. Supernatant protein concentrations were determined after centrifugation at 12,000 rpm for $30 \mathrm{~min}$ with a BCA Protein Assay reagent kit (Thermo Pierce, Rockford, IL, USA). Equal amount of the sample ( $40 \mu \mathrm{g}$ of protein) was separated on gradient sodium dodecyl sulphate-polyacrylamide gels (SDS-PAGE) and transferred onto a polyvinylidenedifluoride (PVDF) membrane, which was then blocked with $5 \%$ skimmed milk solution. Afterward, the membranes were incubated with primary antibodies overnight at $4{ }^{\circ} \mathrm{C}$. The primary antibodies used in this study were rabbit anti-p-GSK-3 $\beta$ (Ser9) (1:1000; Cell Signaling Technologies), rabbit anti-GSK-3 $\beta$ (1:1000; Cell Signaling Technologies), rabbit anti-Bcl-2 (1:1000; SigmaAldrich), mouse anti-Bax (1:50 Sigma-Aldrich), rabbit anti-brain-derived neurotrophic factor (BDNF) IgG (1:1000; Abcam) and mouse anti- $\beta$-actin IgG (1:3000; Santa Cruz Biotechnology). After three washes with TBST buffer, the membranes were incubated with goat anti-mouse HRP or goat anti-rabbit HRP (1:3000; Santa Cruz, Biotechnology) for $30 \mathrm{~min}$ each. The images were digitized from the membrane, and the band intensity was quantified using Gel-Pro Analyzer software, version 3.1 (Media Cybernetics, Bethesda, MD, USA).

\section{Apoptosis assay}

TUNEL assay was performed to analyse cell death according to the manufacturer's instructions using In Situ Apoptosis Detection Kit, POD (Roche Applied Science, Mannheim, Germany). The brain tissues including hippocampal cornuammonis (CA) 1, CA3 and dentate gyrus (DG) were harvested, immersed in $3 \% \mathrm{H}_{2} \mathrm{O}_{2}$ and washed with phosphate-buffered saline (PBS), incubated with proteinase $\mathrm{K}$ solution (Life Technologies, Ambion) at $37^{\circ} \mathrm{C}$ for $20 \mathrm{~min}$. Then, the sections were maintained in TUNEL reaction mixture for $1 \mathrm{~h}$ at $37^{\circ} \mathrm{C}$, followed by incubation in $50 \mu \mathrm{L}$ converter POD for another $30 \mathrm{~min}$ at $37^{\circ} \mathrm{C}$. After washing with $\mathrm{PBS}$, the sections were incubated with diaminobenzidine (DAB) substrate solution for $10 \mathrm{~min}$. Finally, images were taken using an Olympus BX5 imaging system (Olympus America, Melville, NY, USA) at $\times 100$ and $\times 400$ magnification. The number of apoptotic neurons per view was counted using microscopy at $\times 400$ magnification.

\section{Statistical analysis}

All data were analysed by an observer who was blind to the experimental protocol. Statistical calculations were performed using the statistical analysis software GraphPad Prism, version 6.0 (GraphPad, San Diego, CA, USA). Data were expressed as the mean \pm standard error (SE). Intergroup comparisons were conducted by two-way ANOVA (LPS $\times$ APAP) followed by Tukey's post hoc test to determine significant differences between the experimental group. For acquisition training (days -3 to -1 ) and spatial working memory testing (days 1 to 3 ) of the MWM, data were analysed using a two-way ANOVA (treatment $\times$ trial time) with repeated measures (trial days) followed by a Bonferroni post hoc test to analyse the difference in escape latency between each group. $P$ values $<0.05$ were considered statistically significant.

\section{Results}

Spontaneous locomotor activity was not changed $24 \mathrm{~h}$ after LPS administration

To evaluate whether the changes in performance after LPS administration were attributable to changes in spontaneous locomotor activity, the open field test was conducted [37]. No significant difference was observed in locomotor performance (total moving distance and moving duration) $24 \mathrm{~h}$ after LPS treatment between the animals in the LPS, A $+\mathrm{L}, \mathrm{CON}$ and APAP groups (Fig. 1a, b), suggesting that the impaired performance in the LPS group was not a result of reduced locomotor ability.

\section{APAP attenuated LPS administration-induced learning and memory impairment}

Previous work in our laboratory has demonstrated that intracerebroventricular administration of LPS leads to learning and memory deficits [19]. Therefore, the protective effects of APAP on LPS-induced cognitive deficits were examined in this model. As shown in Fig. 2a, in the MWM test, the escape latency in all groups improved over time and was significantly shorter during the third training session than in the first training 

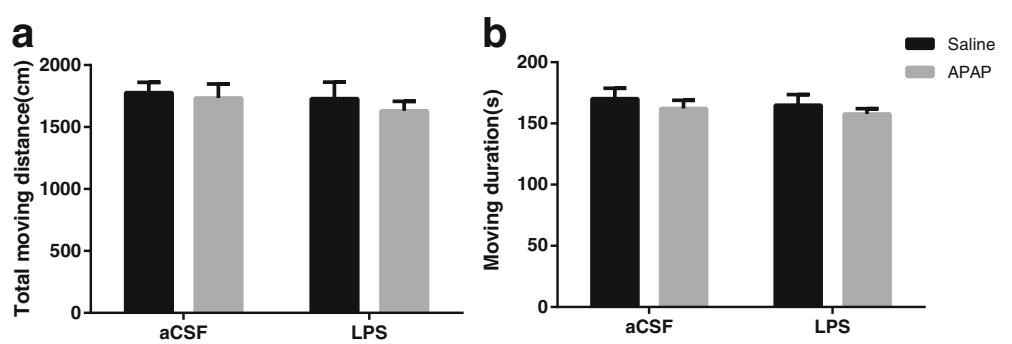

Fig. 1 Determine the effect of LPS and APAP on mice in the open field test. The results of spontaneous locomotor activity showing that neither LPS nor APAP changed the total moving distance (a) or moving duration (b) $24 \mathrm{~h}$ after LPS administration. Data are expressed as the mean \pm SE $(n=10)$. APAP acetaminophen, aCSF artificial cerebrospinal fluid, LPS lipopolysaccharide, SE standard error

a

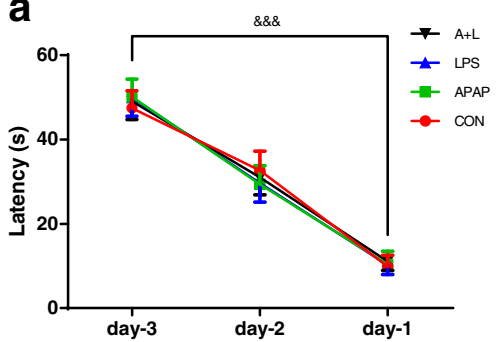

d

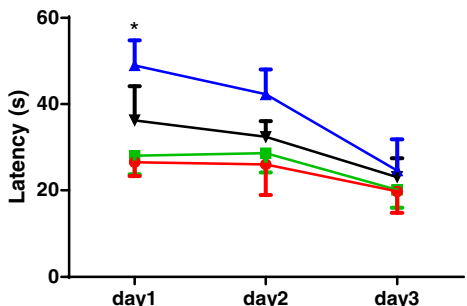

b

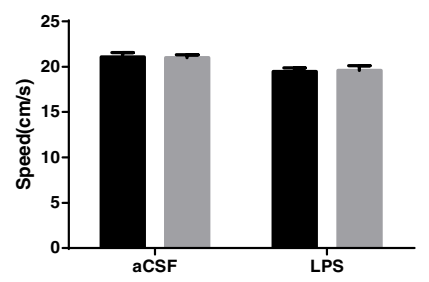

e

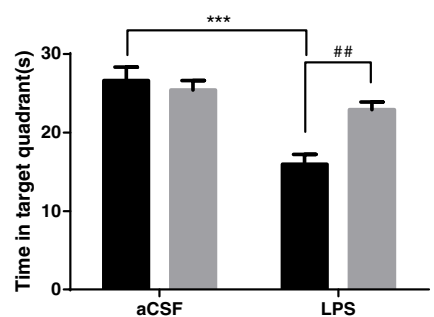

C

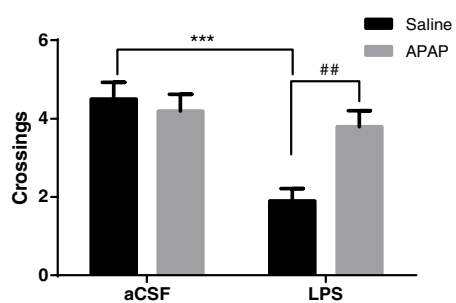

f

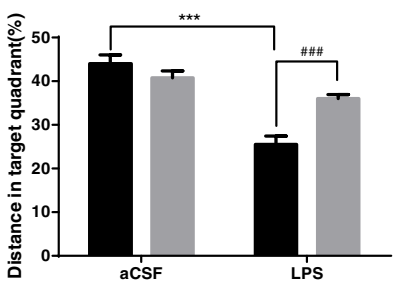

g

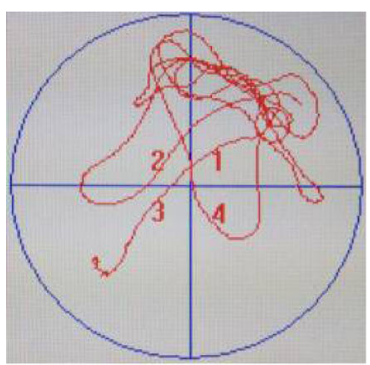

CON h

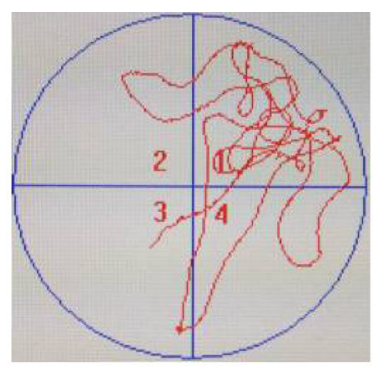

APAP

i

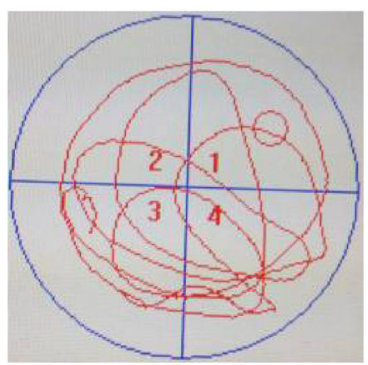

LPS j

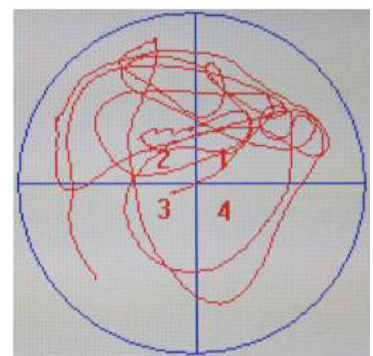

$A+L$

Fig. 2 APAP attenuated behavioural performance after exposure to LPS in mice. a Spatial learning in the MWM on days $-3,-2$ and -1 . Average escape latency (s) is shown for the three training sessions in the maze. $\mathbf{b}$ Swimming speed during probe testing on day 1. $\mathbf{c}$ Platform-site crossings during probe testing on day 1. e Time travelled in the target quadrant during probe testing on day 1. $\mathbf{f}$ Percentage of distance travelled in the target quadrant during probe testing on day 1. $\mathbf{d}$ Latency to the platform during spatial working memory testing on days 1,2 and 3. g-j Representative trajectories of mice from each experimental group during probe testing in which the hidden platform was removed. The circle represents the previous location of the platform. Data are expressed as the mean \pm SE $(n=20)$. ${ }^{*} P<0.05,{ }^{* * *} P<0.001 \mathrm{vs}$. CON group; ${ }^{\# \#} P<0.01,{ }^{\# \# \#} P<0.001$ vs. LPS group; $\& \& \& P<0.001$ vs. training session 1 in day -3 . APAP acetaminophen, aCSF artificial cerebrospinal fluid, LPS lipopolysaccharide, SE standard error 
session $(P<0.001)$, yet no difference was observed between the groups during the same day, indicating that all animals were able to learn where the platform was located. On day 0 , animals underwent microinjection surgery, and on postoperative day 1 , mice were subjected to a probe test for reference memory, during which the platform was absent. In the probe test, there were no significant differences in swimming speed between groups, suggesting again that the poorer performance of the LPS group was not a result of reduced locomotor ability (Fig. 2b). It was observed that APAP prevented memory deficits caused by LPS on postoperative day 1 $\left(F_{\mathrm{LPS}}=14.42, \quad F_{\mathrm{APAP}}=4.101, \quad F_{\mathrm{LPS}} \times \mathrm{APAP}=7.754 \quad\right.$ for platform-site crossings, $P<0.05 ; \quad F_{\mathrm{LPS}}=25.43, \quad F_{\mathrm{APAP}}=$ 4.799, $F_{\mathrm{LPS}} \times \mathrm{APAP}=9.700$ for time travelled in the target quadrant, $P<0.05 ; F_{\mathrm{LPS}}=50.43, F_{\mathrm{APAP}}=4.876, F_{\mathrm{LPS}} \times \mathrm{APAP}$ $=17.53$ for percentage of distance travelled in the target quadrant during probe testing, $P<0.05$; Fig. $2 \mathrm{c}, \mathrm{e}, \mathrm{f})$. On days 1 to 3 , mice were subjected to a working memory test, during which both the platform and mice were randomly placed in a novel position to assess working- or trial-dependent learning and memory. If the animal recalls the sample trial, it will swim a shorter path to the goal on the second trial. On day 1 , it was observed that the escape latency needed to reached the new platform was significantly higher $(P<0.05)$ in the LPS group than in the CON and APAP group, and there was no significant difference in escape latency between the $\mathrm{A}+\mathrm{L}$ group and the CON and APAP group, although mice in the A $+\mathrm{L}$ group exhibited a tendency towards an increase in escape latency (Fig. 2d). On day 2, the escape latency of the LPS group still showed tendency for a higher latency than that of the other groups, although it did not reach statistical significance (Fig. 2d). On day 3, the impaired performance of the LPS group in the working memory test returned to control levels, and there was no significant difference in escape latency among all groups (Fig. 2d).
Collectively, our results suggest that LPS causes cognitive impairment, specifically a deficit in short-term memory retention, which can be ameliorated by APAP treatment.

\section{APAP suppressed the accumulation of pro-inflammatory cytokines induced by LPS in the mouse hippocampus}

We investigated the levels of several pro-inflammatory cytokines (IL-1 $\beta$, IL- 6 and TNF- $\alpha$ ) in the hippocampus, a brain region where neuroinflammation mainly occurs in response to brain injury and inflammation [38, 39]. In accordance with our previous study [19], an ELISA immunoassay showed that the level of IL- $1 \beta\left(F_{\mathrm{LPS}}=60.95\right.$, $P<0.001$, Fig. 3a), IL-6 ( $F_{\text {LPS }}=53.98, P<0.001$, Fig. $\left.3 b\right)$ and TNF- $\alpha\left(F_{\text {LPS }}=163.6, P<0.001\right.$, Fig. $\left.3 c\right)$ in the LPS group was much higher than that in the CON group. Remarkably, APAP significantly attenuated LPS-induced increases in IL-1 $\beta\left(F_{\mathrm{APAP}}=25.65, P<0.001\right.$, Fig. 3a), IL-6 $\left(F_{\mathrm{APAP}}=11.61, P<0.001\right.$, Fig. $\left.3 \mathrm{~b}\right)$ and TNF- $\alpha\left(F_{\mathrm{APAP}}=\right.$ 37.92, $P<0.001$, Fig. $3 \mathrm{c}$ ) levels. These results suggest that APAP inhibited LPS-induced accumulation of proinflammatory cytokines in the mouse hippocampus.

\section{APAP prevented microglial activation after intracerebroventricular administration of LPS}

Due to the important role that cytokines and microglial activation play in LPS-induced neuroinflammation [14, 40-42], we used immunohistochemistry to investigate microglial activation. The immunohistochemistry results showed that LPS caused obvious microglial activation in the mouse hippocampal DG regions $\left(F_{\mathrm{LPS}}=109.7\right.$, $P<0.001)$, CA1 regions $\left(F_{\mathrm{LPS}}=26.93, P<0.001\right)$ and CA3 regions $\left(F_{\mathrm{LPS}}=135.1, P<0.001\right)$ labelled by Iba1 (Fig. $\left.4 \mathrm{~b}\right)$. APAP significantly attenuated LPS-induced microglial activation $\left(F_{\mathrm{APAP}}=5.547\right.$ and $P=0.0211, F_{\mathrm{APAP}}=9.321$ and $P=0.0042$ and $F_{\mathrm{APAP}}=5.098$ and $P=0.0301$ for DG regions, $\mathrm{CA} 1$ regions and $\mathrm{CA} 3$ regions, respectively) in the hippocampus of mice (Fig. 4b).
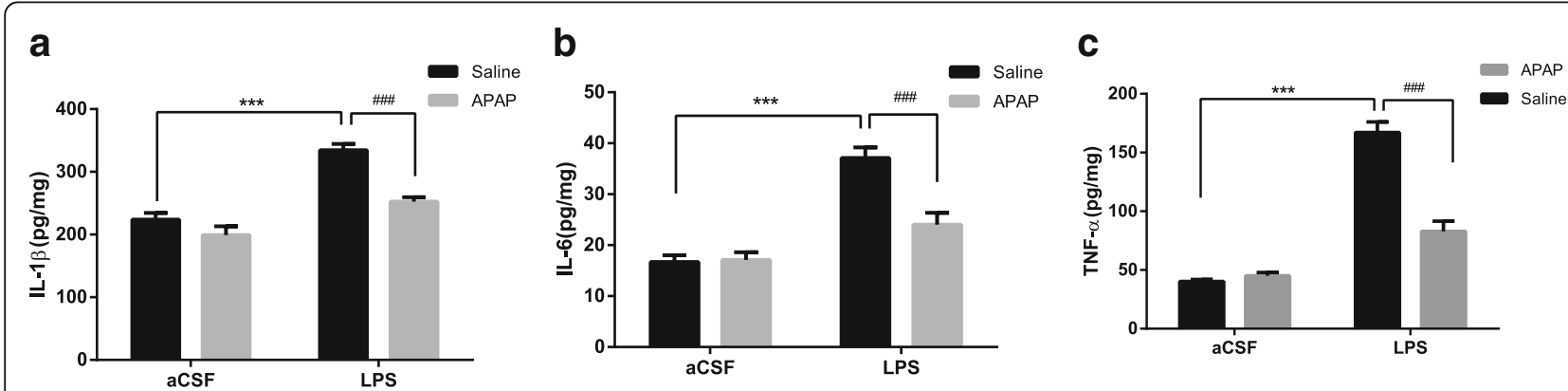

Fig. 3 APAP attenuated the accumulation of pro-inflammatory cytokines induced by LPS in the mouse hippocampus. Levels of IL-1 $\beta$ (a), IL-6 (b) and TNF- $a(\mathbf{c})$ in samples of the hippocampus $6 \mathrm{~h}$ after LPS administration. IL-1 $\beta, \mathrm{IL}-6$ and TNF- $\alpha$ were increased by LPS, and APAP reversed the

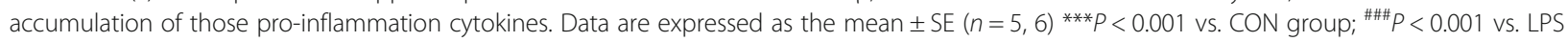
group. APAP acetaminophen, aCSF artificial cerebrospinal fluid, LPS lipopolysaccharide, SE standard error 


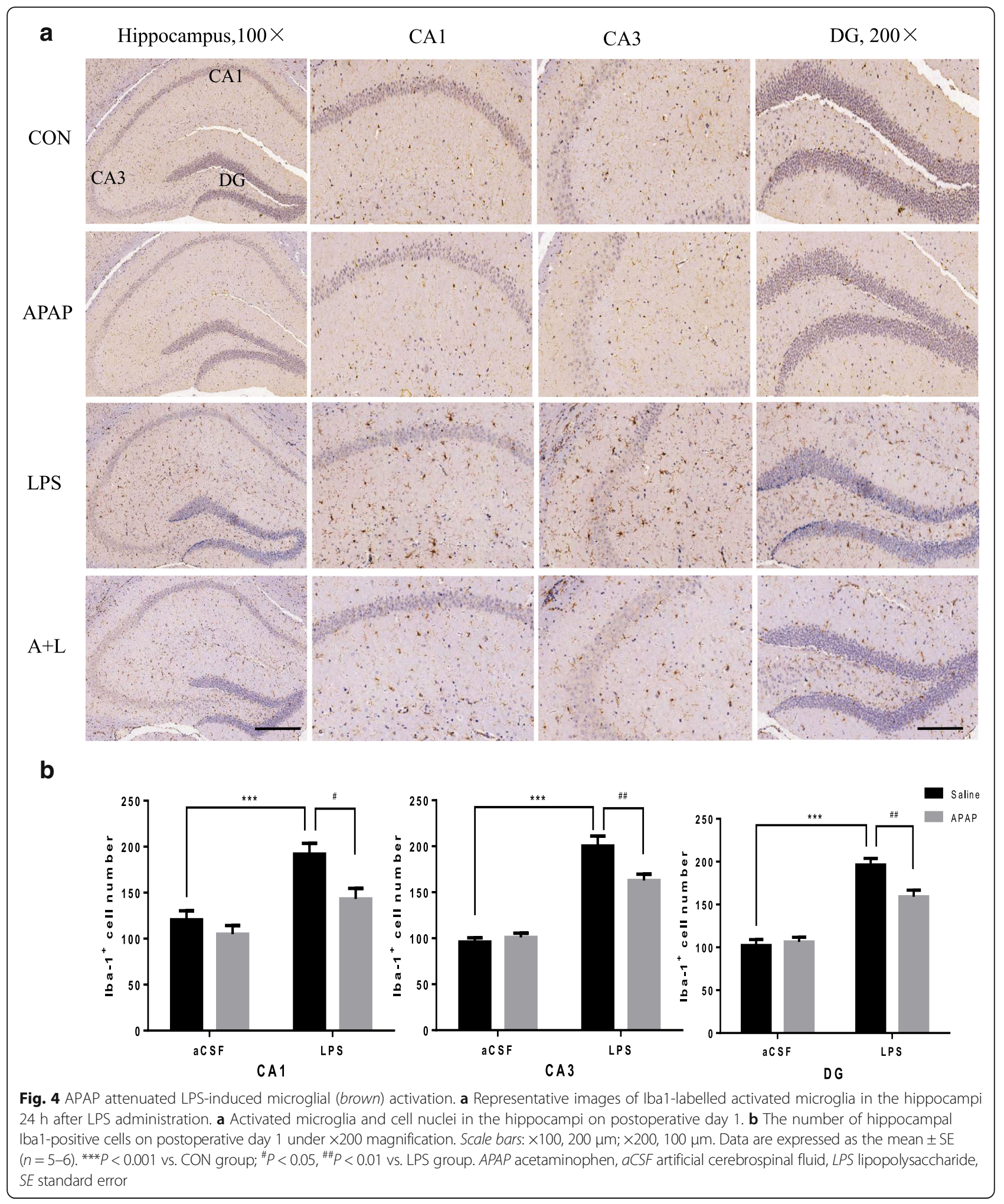

APAP increased SOD activity and reduced MDA levels in the hippocampi of mice after LPS administration

As shown in Fig. 5a, compared to the CON group, LPS induced a significant decrease in SOD activity in the hippocampus on postoperative day $1\left(F_{\mathrm{LPS}}=24.53\right.$, $P<0.001, n=6)$; this abnormal decrease in SOD activity was largely prevented by $\operatorname{APAP}\left(F_{\mathrm{APAP}}=2.737, P=0.0111\right.$, $n=6)$. As demonstrated in Fig. 5b, the MDA level of the 

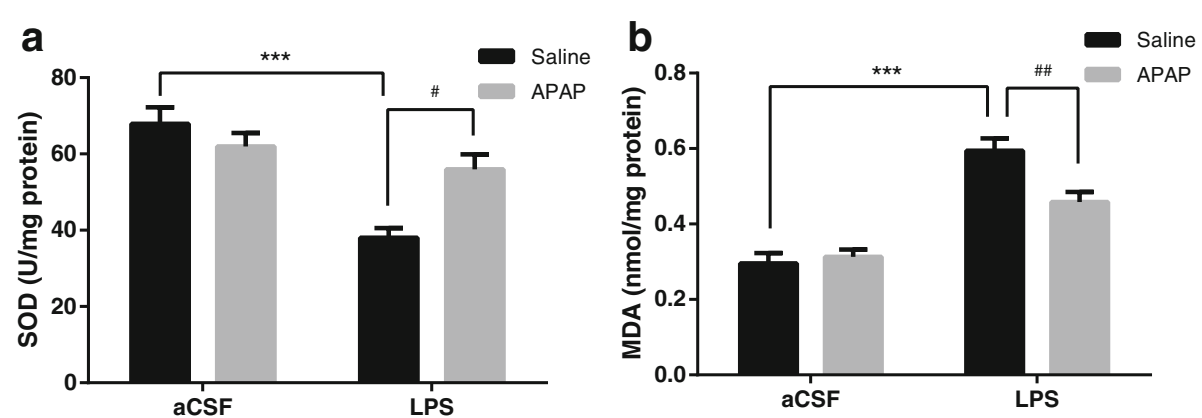

Fig. 5 APAP increased SOD activity and reduced hippocampal MDA levels after exposure to LPS in mice. a SOD activity in the hippocampus on postoperative day 1. b The MDA level in the hippocampus on postoperative day 1 . Data are expressed as the mean $\pm \mathrm{SE}(n=6)$. ${ }^{* *} P<0.001 \mathrm{vs}$. CON group; ${ }^{\#}<0.05,{ }^{\# \#} P<0.01$ vs. LPS group. SOD superoxide dismutase, MDA malondialdehyde, APAP acetaminophen, aCSF artificial cerebrospinal fluid, LPS lipopolysaccharide, SE standard error

hippocampi in the LPS group was significantly higher on postoperative day 1 than that in the CON group $\left(F_{\text {LPS }}=67.35, P<0.001, n=6\right)$. Likewise, APAP significantly attenuated abnormally increased MDA levels in the hippocampi of the $\mathrm{A}+\mathrm{L}$ group $\left(F_{\mathrm{APAP}}=4.796, P=0.0099\right.$, $n=6)$. Meanwhile, no significant difference was found between the APAP alone and CON groups.

\section{APAP blocked glycogen synthase kinase $3 \beta$ (GSK3 $\beta$ ) activity and attenuated the BDNF decrease in mice with LPS-induced hippocampal impairment}

GSK3 $\beta$ is an important kinase that was first identified as the major regulator of glycogen synthase, the key enzyme involved in glycogen synthesis. However, similar to many other kinases, GSK3 $\beta$ was found to regulate numerous other processes, including those involving cell death, apoptosis and cognitive function [43, 44]. Therefore, the present experiments were designed to determine whether APAP is able to modulate GSK3 $\beta$ activity in the LPS-exposed mouse hippocampus. The total expression level of GSK3 $\beta$ was not altered by different treatments $\left(F_{\mathrm{LPS}}=0.17, P>0.05 ; F_{\mathrm{APAP}}=0.01257, P>0.05 ;\right.$ Fig. $\left.6 \mathrm{~d}\right)$, whereas the phospho-GSK3 $\beta /$ GSK3 $\beta$ ratio in the hippocampus of LPS-exposed mice was significantly decreased, and APAP attenuated this reduction $\left(F_{\mathrm{LPS}}=48.37, P<\right.$ $0.001 ; F_{\mathrm{APAP}}=8.867, P=0.0074$; Fig. $\left.6 \mathrm{e}\right)$. These data suggest that APAP treatment downregulates GSK3 $\beta$ activity by phosphorylating GSK3 $\beta$ in the hippocampus. In the LPS-treated hippocampus, total GSK3 $\beta$ remained unchanged, and the activation of GSK3 $\beta$ was relatively higher than in the CON group.

BDNF can enhance protective pathways and inhibit damaging pathways, supporting the survival of existing neurons and promoting neurogenesis $[45,46]$. The effects of LPS and APAP on BDNF were evaluated. The expression of BDNF was reduced in the LPS-treated group, which was alleviated by $\mathrm{APAP}\left(F_{\mathrm{LPS}}=25.73, P<0.001 ; F_{\mathrm{APAP}}=7.706\right.$,
$P=0.0117$; Fig. $6 \mathrm{f})$, suggesting that APAP may protect hippocampal neurons from LPS-induced damage.

\section{APAP significantly decreased the $\mathrm{Bax} / \mathrm{Bcl}-2$ ratio and} neuron apoptosis in the hippocampus of LPS-treated mice To assess whether the balance of hippocampal proapoptotic protein $\mathrm{Bax}$ and anti-apoptotic protein $\mathrm{Bcl}-2$ was affected by LPS, the expression of Bax and Bcl-2 proteins was measured using immunoblotting. As shown in Fig. $7 \mathrm{~d}$, the expression of $\mathrm{Bcl}-2$ protein was significantly decreased in the LPS-treated mice $\left(F_{\mathrm{LPS}}=55.54\right.$, $P<0.001, n=6$ ), whereas APAP treatment was able to restore $\mathrm{Bcl}-2$ protein content to that comparable to the CON group $\left(F_{\mathrm{APAP}}=19.51, P<0.001, n=6\right)$. The expression of Bax protein was not different among the four groups $\left(F_{\mathrm{LPS}}=2.37, \quad F_{\mathrm{APAP}}=0.062, \quad P>0.05, \quad\right.$ Fig. $\left.7 \mathrm{e}\right)$. Further analysis of the $\mathrm{Bax} / \mathrm{Bcl}-2$ ratio, an index of proapoptotic signalling pathway activation [47], demonstrated that the $\mathrm{Bax} / \mathrm{Bcl}-2$ ratio was higher in the LPS group than in the CON group $\left(F_{\mathrm{LPS}}=27.98, P<0.001\right.$, $n=6$, Fig. 7f). APAP treatment significantly decreased the $\mathrm{Bax} / \mathrm{Bcl}-2$ ratio in the hippocampi of the $\mathrm{A}+\mathrm{L}$ group compared to the LPS group $\left(F_{\mathrm{APAP}}=6.140, P=0.0223\right.$, $n=6$, Fig. $7 \mathrm{f})$. In order to observe the effect of APAP on LPS-induced hippocampal neurons, we carried out TUNEL assay. We found that the apoptotic cell number of the DG, CA1 and CA3 regions in the LPS group was significantly higher than that in the CON group $(P<0.001$ for DG regions, $P<0.001$ for CA1 regions and $P=0.0013$ for $\mathrm{CA} 3$ regions, respectively, Fig. 7h). However, APAP significantly attenuated LPS-induced neuron apoptosis in the hippocampal DG, CA1 and CA3 regions $(P=0.0145$ for DG regions, $P=0.0063$ for $C A 1$ regions and $P=0.0109$ for CA3 regions, respectively, Fig. 7h). Our results suggested that APAP may ameliorate the learning and memory ability by reducing LPS-induced hippocampal neuron apoptosis. 


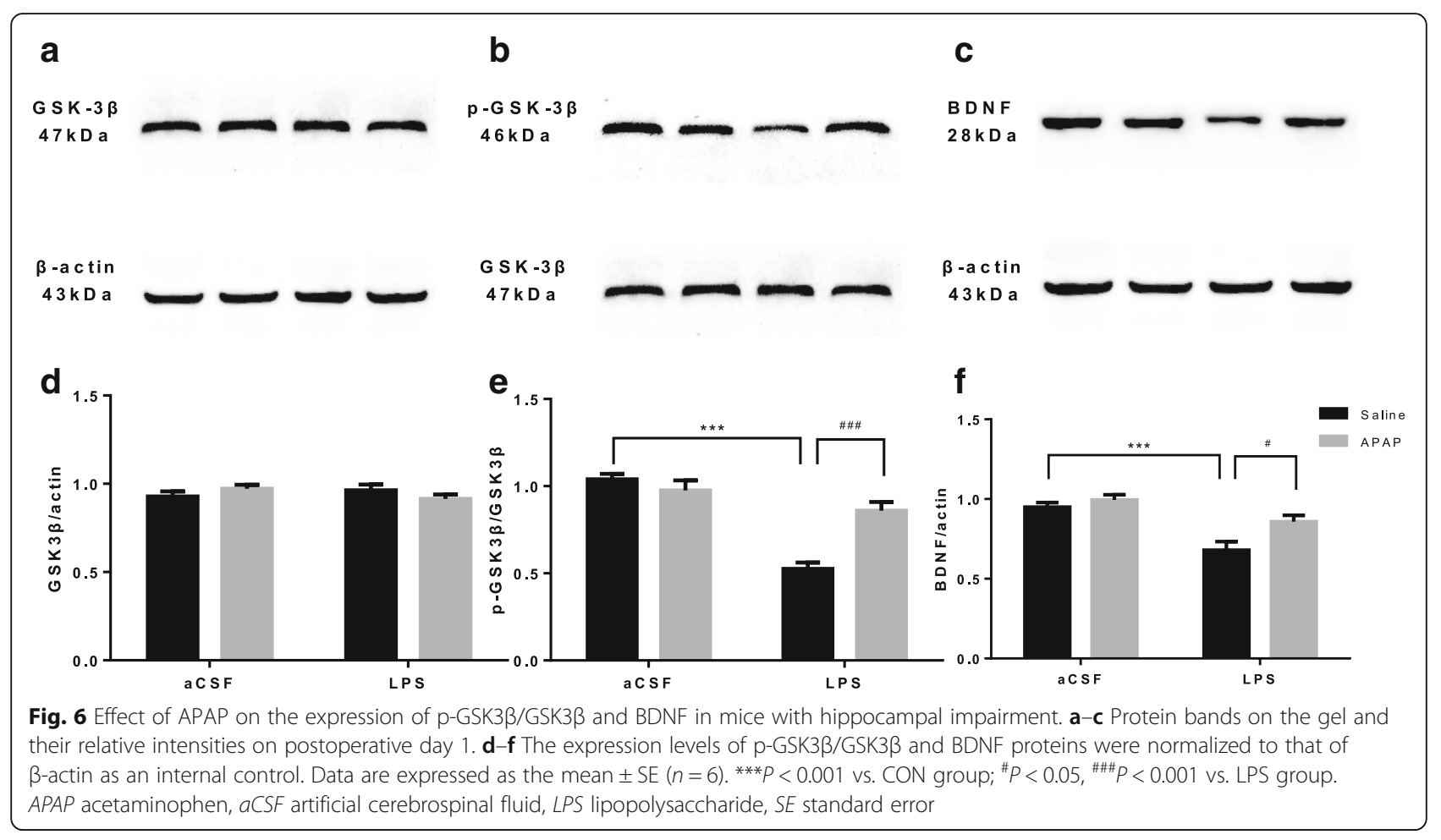

\section{Discussion}

This paper shows that APAP improved cognitive dysfunction induced by cerebroventricular administration of LPS. The protective effects of APAP on cognitive impairment in mice may be related to its antioxidant and antiinflammatory activity, modulating the activity of GSK3 3 , as well as its ability to inhibit the mitochondrial permeability transition (MPT) pore and the subsequent apoptotic pathway.

Recent experimental data suggest that APAP may have several remarkable effects other than its well-known analgesic/antipyretic properties. Thus far, a wide array of neuroprotective effects of APAP has been reported in different studies [24, 27-29, 48]. Previous studies have shown that APAP can protect neurons from degeneration in animal models and cell lines of AD [29] and PD [49] that involves inflammatory and oxidative stress processes. Given the evidence that sepsis can cause cognitive impairment in human subjects [50,51], our study focused on the effects of APAP in an LPS-induced cognitive impairment mouse model.

The MWM test was chosen as a robust and reliable test that is strongly correlated with hippocampal-dependent memory [52, 53]. Escape from water is relatively immune from activity or body mass differences, making it ideal for experimental models. As previously reported [19], there were no significant differences between groups during the acquisition phase, and $2 \mu \mathrm{g}$ of LPS (intracerebroventricular administration) caused memory deficits on postoperative day 1 following the microinjection. In the preliminary experiment, mice treated with $2 \mu \mathrm{g}$ of LPS did not remember where the platform was and searched aimlessly instead. We found that $100 \mathrm{mg} / \mathrm{kg}$ of APAP ameliorated the memory deficits caused by LPS. Similar results were obtained in formal experiments using the spatial reference memory test; an obvious inherent memory impairment was observed in the LPS group, and this inherent memory injury was significantly alleviated by APAP. In the MWM trail-dependent learning task, an obvious impairment in working memory was observed in the LPS group, and this working memory injury was alleviated by APAP although there was no statistical significance. Collectively, our results indicate that LPS causes cognitive impairment, specifically a deficit in short-term memory retention, which can be ameliorated by APAP treatment. This finding suggests a potential application of APAP in patients with or at risk for cognitive impairment. The results of the current study are consistent with a previous study that showed that administration of APAP improves cognitive performance of rodents in the Morris water maze test [48].

Considerable evidence implicates neuroinflammation in the pathophysiology of progressive neurodegenerative disorders such as AD, PD, ALS and MS [5-7]. A link between increased cytokine formation and neurodegeneration has been demonstrated [54]. Thus, we next evaluated the effect of APAP on neuroinflammatory processes induced by LPS administration. Microglia is the 


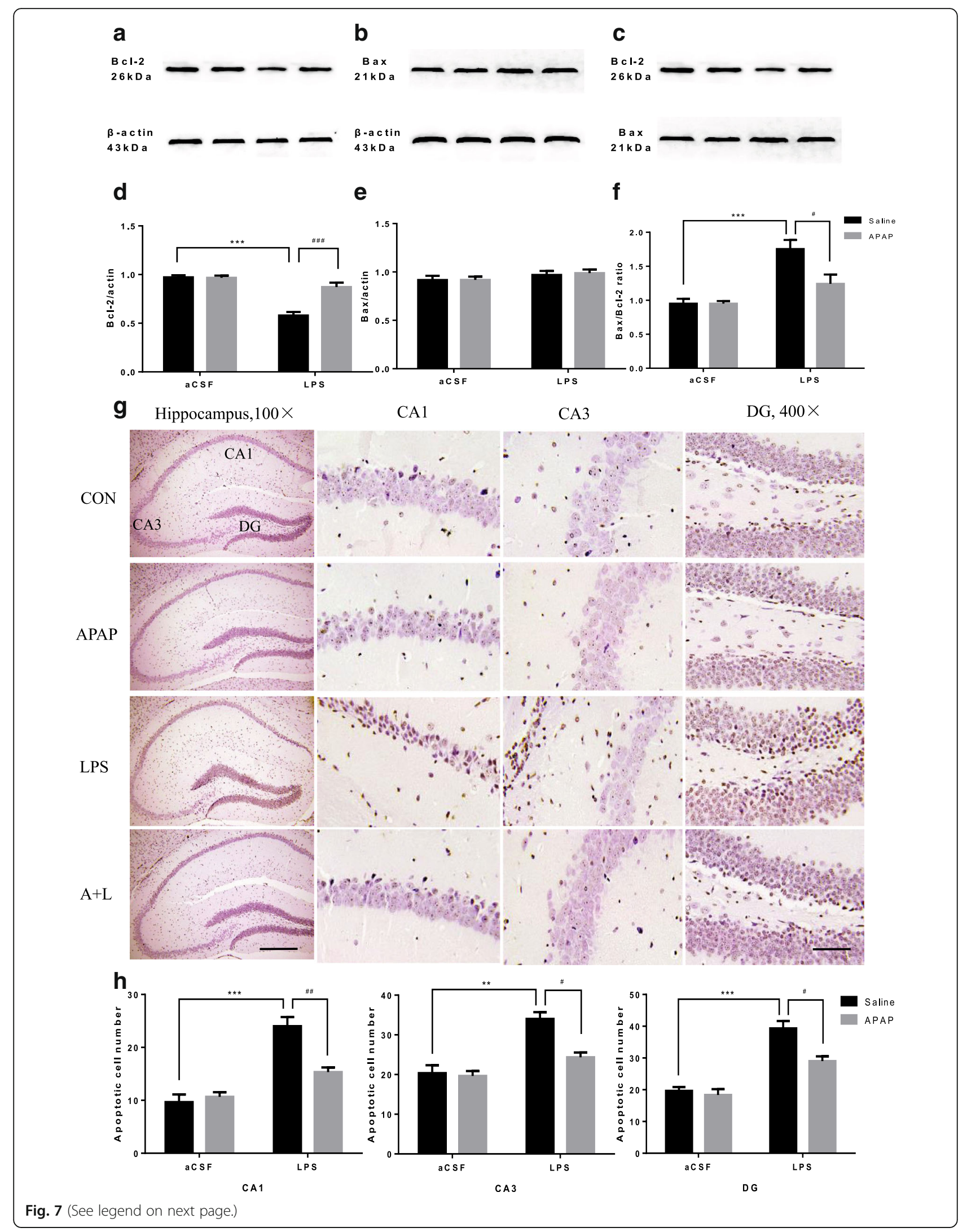


(See figure on previous page.)

Fig. 7 Effect of APAP on the expression of $\mathrm{Bax} / \mathrm{Bcl}-2$ and neuron apoptosis in mice with hippocampal impairment. a-c Protein bands on the gel and their relative intensities on postoperative day 1. $\mathbf{d}-\mathbf{f}$ The expression levels of $\mathrm{Bax} / \mathrm{BCl}-2$ proteins were normalized to that of $\beta$-actin as an internal control. $\mathbf{g}$ CA1, CA3 and DG regions of hippocampal from indicated group of mice. TUNEL staining demonstrated neuron apoptosis on postoperative day 1 . $\mathbf{h}$ The number of hippocampal apoptotic neurons on postoperative day 1 under $\times 400$ magnification. Scale bars: $\times 100$, $200 \mu \mathrm{m} ; \times 400,50 \mu \mathrm{m}$. Data are expressed as the mean \pm SE $(n=6) .{ }^{* *} P<0.01,{ }^{* * *} P<0.001$ vs. CON group; ${ }^{\#} P<0.05,{ }^{\# \#} P<0.01,{ }^{\# \#} P<0.001$ vs. LPS group. APAP acetaminophen, aCSF artificial cerebrospinal fluid, LPS lipopolysaccharide, SE standard error

resident macrophage in the brain, participates in the coordination of events important for the maintenance of neuronal health and plays the most important role in responding to inflammation in the central nervous system. Previous studies [32-35, 41] have shown that LPS triggers microglia activation and consequently induces pro-inflammatory cytokine secretion within $6 \mathrm{~h}$ via the NF- $k B$ pathway in the mouse hippocampus and that the nuclear signal of the transcription factor is strongly reduced or blocked by anti-inflammatory compounds $[55,56]$. In the current study, we demonstrated that intracerebroventricular injection of LPS induced increases in TNF- $\alpha, \mathrm{IL}-1 \beta$ and IL- 6 levels in the mouse brain $6 \mathrm{~h}$ after the injection. In addition, microglia labelled by Iba1 in the hippocampus were activated. The current studies showed that APAP inhibited LPS-induced microglial activation and production of pro-inflammatory mediators including TNF- $\alpha$, IL- $1 \beta$ and IL-6. Our results are in accordance with previous reports that APAP blunted neuronal apoptosis via reduction of the inflammatory transcription factor NF- $\mathrm{KB}$ and reduces inflammatory protein such as chemokines and cytokines [57]. APAP has the capability to modulate the release of inflammatory molecules such as PGE2 and IL- 6 by A $\beta$-stimulated astrocytes [58]. APAP also protects brain endothelial and neuronal cells against oxidative stress, and menadione-induced increase in chemokines and cytokines was reduced by APAP $[25,26]$. Thus, APAP possesses the ability to block NF-kB activation and exert a neuroprotective effect, suggesting that the neuroprotective effects of APAP might be related to its anti-neuroinflammation effects.

Oxidative stress is defined as an imbalance between higher cellular levels of reactive oxygen species (ROS), e.g. superoxide and hydroxyl radicals [59], and cellular antioxidant defence [60]. If ROS are not controlled by enzymatic and non-enzymatic antioxidants, they can cause oxidative injury, i.e. peroxidation of cell membrane phospholipids, proteins (receptors and enzymes) and DNA. The brain is extremely susceptible to oxidative damage induced by ROS because it generates very high levels of ROS due to its very high aerobic metabolism and blood perfusion and its relatively poor enzymatic antioxidant defence [61]. The brain contains polyunsaturated fatty acids (PUFAs), which can readily be peroxidized [62]. Lipid peroxidation (LP) causes injury to cells and intracellular membranes and may lead to cell destruction and subsequently cell death $[59,63]$. Therefore, oxidative stress participates in neuronal injury and cognitive impairment. However, increasing evidence suggests that APAP has unappreciated antioxidant properties. For example, APAP can protect dopaminergic neurons from 1-methyl-4-phenylpyridinium $\left(\mathrm{MPP}^{+}\right)$-induced toxicity in mitochondria by scavenging ROS [23]. Additionally, administration of APAP to rats significantly attenuates quinolinic acid-induced superoxide generation [24]. APAP has been shown to be a potent scavenger of ROS [26]. Previous studies have indicated that after intracerebroventricular injection of LPS, significant changes in oxidative stress markers were found in the hippocampus of mice [19]. Indeed, decreased activity of SOD and increased levels of MDA were found after LPS microinjection in the hippocampi of animals in the LPS group. Abnormal changes in the activity of SOD and the levels of MDA were partially reversed by APAP, suggesting that the neuroprotective effects of APAP might be related to its antioxidant effects.

GSK3 $\beta$ regulates many crucial cellular processes in the brain and plays an important role in the inflammatory process $[64,65]$. GSK-3 $\beta$ overexpression induces apoptosis and causes a reduction in postsynaptic density number and volume in hippocampal granule neurons [66], a phenomenon that may be related to cognitive impairment. GSK3 $\beta$ is constitutively active in the cytoplasm, but its activity can be inhibited by phosphorylation of protein kinase B (Akt) at the site of serine 9 [67]. Our results have shown that intracerebroventricular LPS depressed the phospho-GSK3 $\beta /$ GSK3 $\beta$ ratio in the hippocampus, and dysregulation of this signal transduction pathway could result in failure to adequately repress GSK-3 $\beta$, thus allowing GSK-3 $\beta$ to remain abnormally active. This status has been proven to contribute to various pathologies, including neurodegenerative and cognitive disorders, which is in line with behavioural performance $[65,68]$. However, APAP attenuated the reduction by phosphorylating GSK3 $\beta$ in the hippocampus and blocked GSK-3 $\beta$ activity in response to LPS, thus providing protection from LPS-induced apoptosis and cognitive impairment. This observation might be caused by the antioxidant effects of APAP. It is known that oxidative stress can activate GSK3 $\beta$ by Src- and calcium-dependent mechanisms 
[69]. However, recent studies have shown that APAP could modulate microsomal pores, rectify $\mathrm{Ca}^{2+}$ homeostasis and, therefore, decrease ROS production in the rat hippocampus [70].

BDNF and its signalling pathways are firmly implicated in neuronal differentiation and survival. Numerous pieces of evidence indicate that BDNF regulates both early and late phases of long-term potentiation in the hippocampus [71]. Its regulation of synaptic plasticity may underlie hippocampus-dependent learning and memory. Most studies [17, 72-74], including ours, agreed that LPS injections extensively reduced the expression of BDNF in the brain. This decline was altered by APAP treatment in our study. The underlying mechanism for this effect might be that the active GSK3 $\beta$, caused by LPS injection, phosphorylates the cyclic adenosine monophosphate (cAMP) response element-binding protein (CREB) and could thereby regulate transcription of genes related to synaptic plasticity and neurogenesis, including BDNF [75]. As our results showed, APAP blocked GSK-3 $\beta$ activity in mice with LPS-induced hippocampal impairment. Therefore, the decrease in BDNF was subsequently reversed.

It is well known that LPS causes cognitive lesions and that this process involves apoptosis [76, 77]. A large number of proteins operate in concert to regulate apoptosis. Bcl-2 is of particular interest as it has been reported to be protective against oxidative stress, reducing cell death induced by reactive oxygen species [78-80]. Previous studies have shown that cells overexpressing anti-apoptotic Bcl-2 exhibit a marked reduction in apoptosis, which suggests that anti-apoptotic Bcl-2 could independently affect the rate of apoptosis [81]. Antiapoptotic Bcl-2 family members can attenuate the release of killer proteins, influence mitochondrial integrity and prevent apoptosis [82, 83]. Similar studies employing neuronal cells modelling protein aggregation typical of Alzheimer's disease have also reported a significant reduction in apoptotic cell death when these cells overexpressed anti-apoptotic Bcl-2 [84]. Recent in vitro data have shown that APAP increases expression of antiapoptotic protein $\mathrm{Bcl}-2$ in brain endothelial cells and neuronal cells experiencing oxidative stress as a byproduct of inflammation $[25,26]$. In this paper, our results are consistent with previous studies; we found that LPS-induced cognitive impairment was associated with decreased $\mathrm{Bcl}-2$ expression and an elevated $\mathrm{Bax} / \mathrm{Bcl}-2$ ratio and that APAP protects against apoptosis, thereby assuaging cognitive impairment, by increasing the expression of anti-apoptotic $\mathrm{Bcl}-2$ proteins and decreasing the hippocampal neuron apoptosis. APAP is likely to prevent mitochondrial pore dysfunction, resulting in the stabilization of pro-apoptotic proteins and consequently minimizing their deleterious effects on MPT, which precede apoptosis and necrosis [83].

\section{Conclusions}

In summary, obvious cognitive impairment was shown in mice that underwent intracerebroventricular microinjection of LPS. Our in vivo studies showed that APAP could alleviate cognitive impairment induced by LPS. Its protective mechanism may be related to its antioxidant and anti-inflammatory properties and modulation of GSK3 $\beta$ activity, as well as its ability to inhibit the MPT pore and subsequent apoptotic pathway. Although the molecular mechanisms of action of APAP are controversial due to its hepatotoxicity at high doses [85], further investigation of the neuroprotective activity of APAP in the mammalian system is warranted given the prospect for this common medication to be used for prophylactic, as well as adjuvant, therapy for neurodegenerative diseases resulting from oxidative and inflammatory damage.

\section{Abbreviations}

aCSF: Artificial cerebrospinal fluid; AD: Alzheimer's disease; ALS: Amyotrophic lateral sclerosis; APAP: Acetaminophen; BDNF: Brain-derived neurotrophic factor; CA: Cornuammonis; DG: Dentate gyrus; ELISA: Enzyme-linked immunosorbent assay; GSK3 $\beta$ : Glycogen synthase kinase $3 \beta$;

LPS: Lipopolysaccharide; MDA: Malondialdehyde; MPT: Mitochondrial permeability transition; MS: Multiple sclerosis; MWM: Morris water maze; PD: Parkinson's disease; POCD: Postoperative cognitive dysfunction; SE: Standard error; SOD: Superoxide dismutase

\section{Acknowledgements}

The authors thank Li-Jun Sun for providing the MWM equipment and Lei Li for analyzing the result of immunohistochemistry staining. The authors have no conflicting financial interests.

\section{Funding}

This research was conducted with the support of National Natural Science Foundation of China (Nos. 81371204, 81471119).

\section{Availability of data and materials}

The datasets during and/or analysed during the current study are available from the corresponding author on reasonable request.

\section{Authors' contributions}

WXZ conceived the study, designed the experiment, carried out the MWM, ELISA and Western blotting measurement and drafted the manuscript. JHZ performed the open field test, immunohistochemistry measurement and analysis of these data and drafted the manuscript. JBC participated in formulating the design of the studies, interpretation of results and manuscript editing. WW contributed to perform the statistical analysis and manuscript editing. DXW contributed to the design of the studies and manuscript editing. XYZ prepared the animal models and contributed to date the analysis. JY and YYZ helped to perform the tissue sampling, biochemical analysis and interpretation. YZZ contributed to the data interpretation and manuscript editing, helped funding for the project and helped to draft the manuscript. WDM conceived of the study, participated in its design and coordination, secured funding for the project, helped to draft the manuscript and took overall responsibility for the work. All authors read and approved the final manuscript.

\section{Competing interests}

The authors declare that they have no competing interests.

\section{Consent for publication}

Not applicable.

\section{Ethics approval and consent to participate}

The procedures on animal experimentation were approved by the Animal Care Committee of the Chinese People's Liberation Army General Hospital (Beijing, China). The maintenance and handling of the mice were consistent 
with the guidelines of the National Institutes of Health, and adequate measures were taken to minimize animal discomfort.

\section{Author details}

${ }^{1}$ Anesthesia and Operation Center, Chinese PLA General Hospital, 28th Fuxing Road, Haidian District, Beijing 100853, China. ${ }^{2}$ The Second Affiliated Hospital of Xiangya School of Medicine, Central South University, Changsha 410008, China. ${ }^{3}$ Department of Anesthesiology, The General Hospital of the PLA Rocket Force, Beijing 100088, China. ${ }^{4}$ Department of Anesthesiology and Surgical Intensive Care, Peking University First Hospital, Beijing 100034, China ${ }^{5}$ Institute of Pharmacology and Toxicology, Beijing Key laboratory of Neuropsychopharmacology, 27th Taiping Road, Haidian District, Beijing 100850, China.

Received: 10 September 2016 Accepted: 16 December 2016 Published online: 21 January 2017

\section{References}

1. Shoair OA, Grasso li MP, Lahaye LA, Daniel R, Biddle CJ, Slattum PW Incidence and risk factors for postoperative cognitive dysfunction in older adults undergoing major noncardiac surgery: a prospective study. J Anaesthesiol Clin Pharmacol. 2015:31:30-6.

2. Hovens IB, Schoemaker RG, van der Zee EA, Heineman E, Izaks GJ van Leeuwen BL. Thinking through postoperative cognitive dysfunction: how to bridge the gap between clinical and pre-clinical perspectives. Brain Behav Immun. 2012;26:1169-79.

3. Moller JT, Cluitmans P, Rasmussen LS, Houx P, Rasmussen H, Canet J, Rabbitt P, Jolles J, Larsen K, Hanning CD, et al. Long-term postoperative cognitive dysfunction in the elderly ISPOCD1 study. ISPOCD investigators. International Study of Post-Operative Cognitive Dysfunction. Lancet. 1998; 351:857-61.

4. Steinmetz J, Christensen KB, Lund T, Lohse N, Rasmussen LS, Group I. Long-term consequences of postoperative cognitive dysfunction. Anesthesiology. 2009;110:548-55.

5. Gao HM, Hong JS. Why neurodegenerative diseases are progressive: uncontrolled inflammation drives disease progression. Trends Immunol. 2008:29:357-65.

6. Infante-Duarte C, Waiczies S, Wuerfel J, Zipp F. New developments in understanding and treating neuroinflammation. J Mol Med (Berl). 2008;86:975-85

7. Skaper SD. The brain as a target for inflammatory processes and neuroprotective strategies. Ann N Y Acad Sci. 2007;1122:23-34.

8. Peng S, Zhao S, Yan F, Cheng J, Huang L, Chen H, Liu Q, Ji X, Yuan Z. HDAC2 selectively regulates FOXO3a-mediated gene transcription during oxidative stress-induced neuronal cell death. J Neurosci. 2015;35:1250-9.

9. Xia SF, Xie ZX, Qiao Y, Li LR, Cheng XR, Tang X, Shi YH, Le GW. Differentia effects of quercetin on hippocampus-dependent learning and memory in mice fed with different diets related with oxidative stress. Physiol Behav. 2015:138:325-31.

10. Wang P, Cao J, Liu N, Ma L, Zhou X, Zhang H, Wang Y. Protective effects of edaravone in adult rats with surgery and lipopolysaccharide administrationinduced cognitive function impairment. PLoS One. 2016;11:e0153708.

11. Godbout JP, Chen J, Abraham J, Richwine AF, Berg BM, Kelley KW, Johnson RW Exaggerated neuroinflammation and sickness behavior in aged mice following activation of the peripheral innate immune system. FASEB J. 2005:19:1329-31.

12. Ullah F, Ali T, Ullah N, Kim MO. Caffeine prevents d-galactose-induced cognitive deficits, oxidative stress, neuroinflammation and neurodegeneration in the adult rat brain. Neurochem Int. 2015;90:114-24.

13. Banoub JH, El Aneed A, Cohen AM, Joly N. Structural investigation of bacterial lipopolysaccharides by mass spectrometry and tandem mass spectrometry. Mass Spectrom Rev. 2010;29:606-50.

14. Belarbi K, Jopson T, Tweedie D, Arellano C, Luo W, Greig NH, Rosi S TNF-alpha protein synthesis inhibitor restores neuronal function and reverses cognitive deficits induced by chronic neuroinflammation. J Neuroinflammation. 2012;9:23

15. Bossu P, Cutuli D, Palladino I, Caporali P, Angelucci F, Laricchiuta D, Gelfo F De Bartolo P, Caltagirone C, Petrosini L. A single intraperitoneal injection of endotoxin in rats induces long-lasting modifications in behavior and brain protein levels of TNF-alpha and IL-18. J Neuroinflammation. 2012;9:101.

16. Huang $\mathrm{HJ}$, Chen $\mathrm{YH}$, Liang KC, Jheng YS, Jhao J J Su MT, Lee-Chen GJ, Hsieh-Li HM. Exendin-4 protected against cognitive dysfunction in hyperglycemic mice receiving an intrahippocampal lipopolysaccharide injection. PLoS One. 2012;7:e39656.

17. Schnydrig S, Korner L, Landweer S, Ernst B, Walker G, Otten U, Kunz D. Peripheral lipopolysaccharide administration transiently affects expression of brain-derived neurotrophic factor, corticotropin and proopiomelanocortin in mouse brain. Neurosci Lett. 2007:429:69-73.

18. Semmler A, Frisch C, Debeir T, Ramanathan M, Okulla T, Klockgether T, Heneka MT. Long-term cognitive impairment, neuronal loss and reduced cortical cholinergic innervation after recovery from sepsis in a rodent model. Exp Neurol. 2007;204:733-40.

19. Zhang XY, Cao JB, Zhang LM, Li YF, Mi WD. Deferoxamine attenuates lipopolysaccharide-induced neuroinflammation and memory impairment in mice. J Neuroinflammation. 2015:12:20.

20. Hritcu L, Ciobica A, Stefan M, Mihasan M, Palamiuc L, Nabeshima T. Spatial memory deficits and oxidative stress damage following exposure to lipopolysaccharide in a rodent model of Parkinson's disease. Neurosc Res. 2011:71:35-43.

21. Maesschalck PJ. Efficacy and safety of ibuprofen and paracetamol in fever among children. J Pharm Belg. 2011:2:44-5.

22. Blough ER, Wu M. Acetaminophen: beyond pain and fever-relieving. Front Pharmacol. 2011:2:72

23. Maharaj DS, Saravanan KS, Maharaj H, Mohanakumar KP, Daya S. Acetaminophen and aspirin inhibit superoxide anion generation and lipid peroxidation, and protect against 1-methyl-4-phenyl pyridinium-induced dopaminergic neurotoxicity in rats. Neurochem Int. 2004;44:355-60.

24. Maharaj H, Maharaj DS, Daya S. Acetylsalicylic acid and acetaminophen protect against oxidative neurotoxicity. Metab Brain Dis. 2006;21:189-99.

25. Tripathy D, Grammas P. Acetaminophen inhibits neuronal inflammation and protects neurons from oxidative stress. J Neuroinflammation. 2009:6:10.

26. Tripathy D, Grammas P. Acetaminophen protects brain endothelial cells against oxidative stress. Microvasc Res. 2009:77:289-96.

27. Naziroglu M, Uguz AC, Kocak A, Bal R. Acetaminophen at different doses protects brain microsomal $\mathrm{Ca}^{2+}$-ATPase and the antioxidant redox system in rats. J Membr Biol. 2009;231:57-64.

28. Locke CJ, Fox SA, Caldwell GA, Caldwell KA. Acetaminophen attenuates dopamine neuron degeneration in animal models of Parkinson's disease. Neurosci Lett. 2008:439:129-33.

29. Pitchaimani V, Arumugam S, Thandavarayan RA, Thiyagarajan MK, Aiyalu R, Sreedhar R, Nakamura T, Watanabe K. Nootropic activity of acetaminophen against colchicine induced cognitive impairment in rats. J Clin Biochem Nutr. 2012:50:241-4.

30. Chaviaras S, Mak P, Ralph D, Krishnan L, Broadbear JH. Assessing the antidepressant-like effects of carbetocin, an oxytocin agonist, using a modification of the forced swimming test. Psychopharmacology (Berl). 2010;210:35-43

31. Vorhees CV, Williams MT. Morris water maze: procedures for assessing spatial and related forms of learning and memory. Nat Protoc. 2006;1:848-58.

32. Hua F, Wang J, Ishrat T, Wei W, Atif F, Sayeed I, Stein DG. Genomic profile of Toll-like receptor pathways in traumatically brain-injured mice: effect of exogenous progesterone. J Neuroinflammation. 2011:8:42.

33. Skelly DT, Hennessy E, Dansereau MA, Cunningham C. A systematic analysis of the peripheral and CNS effects of systemic LPS, IL-1beta, [corrected] TNF-alpha and IL-6 challenges in C57BL/6 mice. PLoS One. 2013;8:e69123.

34. Norden DM, Trojanowski PJ, Villanueva E, Navarro E, Godbout JP. Sequential activation of microglia and astrocyte cytokine expression precedes increased lba-1 or GFAP immunoreactivity following systemic immune challenge. Glia. 2016;64:300-16.

35. Lawson MA, McCusker RH, Kelley KW. Interleukin-1 beta converting enzyme is necessary for development of depression-like behavior following intracerebroventricular administration of lipopolysaccharide to mice. J Neuroinflammation. 2013;10:54.

36. Reiter RJ, Melchiorri D, Sewerynek E, Poeggeler B, Barlow-Walden L, Chuang J, Ortiz GG, Acuna-Castroviejo D. A review of the evidence supporting melatonin's role as an antioxidant. J Pineal Res. 1995:18:1-11.

37. Zhang C, Li C, Xu Z, Zhao S, Li P, Cao J, Mi W. The effect of surgical and psychological stress on learning and memory function in aged C57BL/6 mice. Neuroscience. 2016;320:210-20.

38. McGeer PL, McGeer EG. Inflammation and the degenerative diseases of aging. Ann N Y Acad Sci. 2004;1035:104-16. 
39. Ren L, Lubrich B, Biber K, Gebicke-Haerter PJ. Differential expression of inflammatory mediators in rat microglia cultured from different brain regions. Brain Res Mol Brain Res. 1999;65:198-205.

40. Raber J, Sorg O, Horn TF, Yu N, Koob GF, Campbell IL, Bloom FE. Inflammatory cytokines: putative regulators of neuronal and neuro-endocrine function. Brain Res Brain Res Rev. 1998;26:320-6.

41. Rosi S, Vazdarjanova A, Ramirez-Amaya V, Worley PF, Barnes CA, Wenk GL. Memantine protects against LPS-induced neuroinflammation, restores behaviorally-induced gene expression and spatial learning in the rat. Neuroscience. 2006;142:1303-15.

42. Zielasek J, Hartung HP. Molecular mechanisms of microglial activation. Adv Neuroimmunol. 1996;6:191-22.

43. Frame $\mathrm{S}$, Cohen P. GSK3 takes centre stage more than 20 years after its discovery. Biochem J. 2001;359:1-16.

44. Jope RS, Johnson GV. The glamour and gloom of glycogen synthase kinase3. Trends Biochem Sci. 2004;29:95-102.

45. Bath KG, Akins MR, Lee FS. BDNF control of adult SVZ neurogenesis. Dev Psychobiol. 2012;54:578-89.

46. Benraiss A, Chmielnicki E, Lerner K, Roh D, Goldman SA. Adenoviral brainderived neurotrophic factor induces both neostriatal and olfactory neuronal recruitment from endogenous progenitor cells in the adult forebrain. J Neurosci. 2001;21:6718-31.

47. Wang Y, Liu X, Zhang D, Chen J, Liu S, Berk M. The effects of apoptosis vulnerability markers on the myocardium in depression after myocardial infarction. BMC Med. 2013;11:32.

48. Ishida T, Sato T, Irifune M, Tanaka K, Nakamura N, Nishikawa T. Effect of acetaminophen, a cyclooxygenase inhibitor, on Morris water maze task performance in mice. J Psychopharmacol. 2007;21:757-67.

49. Casper D, Yaparpalvi U, Rempel N, Werner P. Ibuprofen protects dopaminergic neurons against glutamate toxicity in vitro. Neurosci Lett. 2000;289:201-4

50. Hernandes MS, D'Avila JC, Trevelin SC, Reis PA, Kinjo ER, Lopes LR, Castro-Faria-Neto HC, Cunha FQ, Britto LR, Bozza FA. The role of Nox2derived ROS in the development of cognitive impairment after sepsis. J Neuroinflammation. 2014;11:36.

51. Pinheiro da Silva F, Machado MC, Velasco IT. Neuropeptides in sepsis: from brain pathology to systemic inflammation. Peptides. 2013;44:135-8.

52. Brandeis $R$, Brandys $Y$, Yehuda $S$. The use of the Morris water maze in the study of memory and learning. Int J Neurosci. 1989;48:29-69.

53. Dong Z, Bai Y, Wu X, Li H, Gong B, Howland JG, Huang Y, He W, Li T, Wang YT. Hippocampal long-term depression mediates spatial reversal learning in the Morris water maze. Neuropharmacology. 2013;64:65-73.

54. da Silva DJ, Borges AF, Souza PO, de Souza PR, Cardoso CR, Dorta ML, de Oliveira MA, Teixeira AL, Ribeiro-Dias F. Decreased Toll-like receptor 2 and Toll-like receptor 7/8-induced cytokines in Parkinson's disease patients. Neuroimmunomodulation. 2016;23:58-66.

55. McGeer PL. Cyclo-oxygenase-2 inhibitors: rationale and therapeutic potential for Alzheimer's disease. Drugs Aging. 2000;17:1-11.

56. McGeer PL, McGeer EG. Inflammation of the brain in Alzheimer's disease: implications for therapy. J Leukoc Biol. 1999;65:409-15.

57. Bisaglia M, Venezia V, Piccioli P, Stanzione S, Porcile C, Russo C, Mancini F, Milanese C, Schettini G. Acetaminophen protects hippocampal neurons and PC12 cultures from amyloid beta-peptides induced oxidative stress and reduces NF-kappaB activation. Neurochem Int. 2002;41:43-54.

58. Landolfi C, Soldo L, Polenzani L, Apicella C, Capezzone de Joannon A, Coletta I, Di Cesare F, Brufani M, Pinza M, Milanese C. Inflammatory molecule release by beta-amyloid-treated T98G astrocytoma cells: role of prostaglandins and modulation by paracetamol. Eur J Pharmacol. 1998:360:55-64.

59. Yatin SM, Varadarajan S, Butterfield DA. Vitamin E prevents Alzheimer's amyloid beta-peptide (1-42)-induced neuronal protein oxidation and reactive oxygen species production. J Alzheimers Dis. 2000;2:123-31.

60. Khan MS, Ali T, Kim MW, Jo MH, Jo MG, Badshah H, Kim MO. Anthocyanins protect against LPS-induced oxidative stress-mediated neuroinflammation and neurodegeneration in the adult mouse cortex. Neurochem Int. 2016;100:1-10.

61. Rimessi A, Previati M, Nigro F, Wieckowski MR, Pinton P. Mitochondrial reactive oxygen species and inflammation: molecular mechanisms, diseases and promising therapies. Int J Biochem Cell Biol. 2016;81:281-93.

62. Ozmen I, Naziroglu M, Alici HA, Sahin F, Cengiz M, Eren I. Spinal morphine administration reduces the fatty acid contents in spinal cord and brain by increasing oxidative stress. Neurochem Res. 2007:32:19-25.
63. Eren I, Naziroglu M, Demirdas A. Protective effects of lamotrigine, aripiprazole and escitalopram on depression-induced oxidative stress in rat brain. Neurochem Res. 2007:32:1188-95.

64. Jope RS, Yuskaitis CJ, Beurel E. Glycogen synthase kinase-3 (GSK3): inflammation, diseases, and therapeutics. Neurochem Res. 2007;32:577-95.

65. Martin M, Rehani K, Jope RS, Michalek SM. Toll-like receptor-mediated cytokine production is differentially regulated by glycogen synthase kinase 3. Nat Immunol. 2005;6:777-84.

66. Llorens-Martin M, Fuster-Matanzo A, Teixeira CM, Jurado-Arjona J, Ulloa F, Defelipe J, Rabano A, Hernandez F, Soriano E, Avila J. GSK-3beta overexpression causes reversible alterations on postsynaptic densities and dendritic morphology of hippocampal granule neurons in vivo. Mol Psychiatry. 2013;18:451-60.

67. Frame $\mathrm{S}$, Cohen P, Biondi RM. A common phosphate binding site explains the unique substrate specificity of GSK3 and its inactivation by phosphorylation. Mol Cell. 2001;7:1321-7.

68. He Y, Zhou A, Jiang W. Toll-like receptor 4-mediated signaling participates in apoptosis of hippocampal neurons. Neural Regen Res. 2013;8:2744-53.

69. Grimes CA, Jope RS. The multifaceted roles of glycogen synthase kinase 3beta in cellular signaling. Prog Neurobiol. 2001;65:391-426.

70. Maharaj H, Maharaj DS, Daya S. Acetylsalicylic acid and acetaminophen protect against MPP ${ }^{+}$-induced mitochondrial damage and superoxide anion generation. Life Sci. 2006;78:2438-43.

71. Leal G, Afonso PM, Salazar IL, Duarte CB. Regulation of hippocampal synaptic plasticity by BDNF. Brain Res. 2015;1621:82-101.

72. Guan Z, Fang J. Peripheral immune activation by lipopolysaccharide decreases neurotrophins in the cortex and hippocampus in rats. Brain Behav Immun. 2006;20:64-71.

73. Ma L, Zhang $H$, Liu N, Wang PQ, Guo WZ, Fu Q, Jiao LB, Ma YQ, Mi WD. TSPO ligand PK11195 alleviates neuroinflammation and beta-amyloid generation induced by systemic LPS administration. Brain Res Bull. 2016;121:192-200.

74. Wu CW, Chen YC, Yu L, Chen HI, Jen CJ, Huang AM, Tsai HJ, Chang YT, Kuo YM. Treadmill exercise counteracts the suppressive effects of peripheral lipopolysaccharide on hippocampal neurogenesis and learning and memory. J Neurochem. 2007;103:2471-81.

75. Scott Bitner R. Cyclic AMP response element-binding protein (CREB) phosphorylation: a mechanistic marker in the development of memory enhancing Alzheimer's disease therapeutics. Biochem Pharmacol. 2012;83: 705-14

76. Wang G, Wang W, Zhao J, Ni Y, Zhou X, Zhang W. Ghrelin prevents neuronal apoptosis and cognitive impairments in sepsis-associated encephalopathy. Neuroreport. 2011;22:959-64.

77. Zhou TF, Yu JG. Recombinant human erythropoietin attenuates neuronal apoptosis and cognitive defects via JAK2/STAT3 signaling in experimental endotoxemia. J Surg Res. 2013;183:304-12.

78. Ghate NB, Das A, Chaudhuri D, Panja S, Mandal N. Sundew plant, a potential source of anti-inflammatory agents, selectively induces G2/M arrest and apoptosis in MCF-7 cells through upregulation of $\mathrm{p} 53$ and $\mathrm{Bax} / \mathrm{BCl}-2$ ratio. Cell Death Discov. 2016;2:15062.

79. Hockenbery DM, Oltvai ZN, Yin XM, Milliman CL, Korsmeyer SJ. BCl-2 functions in an antioxidant pathway to prevent apoptosis. Cell. 1993;75:241-51.

80. Park JR, Hockenbery DM. BCL-2, a novel regulator of apoptosis. J Cell Biochem. 1996;60:12-7.

81. Kang MH, Reynolds CP. BCl-2 inhibitors: targeting mitochondrial apoptotic pathways in cancer therapy. Clin Cancer Res. 2009;15:1126-32.

82. Zhang H, Li Q, Li Z, Mei Y, Guo Y. The protection of BCl-2 overexpression on rat cortical neuronal injury caused by analogous ischemia/reperfusion in vitro. Neurosci Res. 2008:62:140-6.

83. Baliga SS, Jaques-Robinson KM, Hadzimichalis NM, Golfetti R, Merrill GF. Acetaminophen reduces mitochondrial dysfunction during early cerebral postischemic reperfusion in rats. Brain Res. 2010;1319:142-54.

84. Rohn TT, Vyas V, Hernandez-Estrada T, Nichol KE, Christie LA, Head E. Lack of pathology in a triple transgenic mouse model of Alzheimer's disease after overexpression of the anti-apoptotic protein BCl-2. J Neurosci. 2008:28:3051-9.

85. Ghanem $\mathrm{Cl}$, Perez MJ, Manautou JE, Mottino AD. Acetaminophen from liver to brain: new insights into drug pharmacological action and toxicity. Pharmacol Res. 2016:109:119-31. 